\title{
Article \\ Circulating miRNA as Biomarkers for Colorectal Cancer Diagnosis and Liver Metastasis
}

\author{
Farah J. Nassar ${ }^{1}$, Zahraa S. Msheik ${ }^{2}{ }^{\circledR}$, Maha M. Itani ${ }^{2}$, Remie El Helou ${ }^{1}$, Ruba Hadla ${ }^{1}{ }^{(D}$, Firas Kreidieh ${ }^{1}$, \\ Rachelle Bejjany ${ }^{1}$, Deborah Mukherji ${ }^{1}{ }^{1}$, Ali Shamseddine ${ }^{1}\left(\mathbb{D}\right.$, Rihab R. Nasr ${ }^{2, *}{ }^{(0)}$ and Sally N. Temraz ${ }^{1, *}$ \\ 1 Department of Internal Medicine, Faculty of Medicine, American University of Beirut, Beirut 1107 2020, \\ Lebanon; fjn00@mail.aub.edu (F.J.N.); rla06@mail.aub.edu (R.E.H.); rah117@mail.aub.edu (R.H.); \\ fk30@aub.edu.lb (F.K.); rb62@aub.edu.lb (R.B.); dm25@aub.edu.lb (D.M.); as04@aub.edu.lb (A.S.) \\ 2 Department of Anatomy, Cell Biology and Physiological Sciences, Faculty of Medicine, American University \\ of Beirut, Beirut 1107 2020, Lebanon; zsm10@mail.aub.edu (Z.S.M.); mmi40@mail.aub.edu (M.M.I.) \\ * Correspondence: rn03@aub.edu.lb (R.R.N.); st29@aub.edu.lb (S.N.T.)
}

Citation: Nassar, F.J.; Msheik, Z.S.; Itani, M.M.; Helou, R.E.; Hadla, R.; Kreidieh, F.; Bejjany, R.; Mukherji, D.; Shamseddine, A.; Nasr, R.R.; et al. Circulating miRNA as Biomarkers for Colorectal Cancer Diagnosis and Liver Metastasis. Diagnostics 2021, 11, 341. https://doi.org/10.3390/ diagnostics11020341

Academic Editor: Andrea Angius Received: 15 January 2021

Accepted: 7 February 2021

Published: 19 February 2021

Publisher's Note: MDPI stays neutral with regard to jurisdictional claims in published maps and institutional affiliations.

Copyright: (c) 2021 by the authors. Licensee MDPI, Basel, Switzerland. This article is an open access article distributed under the terms and conditions of the Creative Commons Attribution (CC BY) license (https:/ / creativecommons.org/licenses/by/ $4.0 /)$.

\begin{abstract}
Colorectal cancer (CRC) is the second leading cause of cancer deaths worldwide. Stage IV CRC patients have poor prognosis with a five-year survival rate of $14 \%$. Liver metastasis is the main cause of mortality in CRC patients. Since current screening tests have several drawbacks, effective stable non-invasive biomarkers such as microRNA (miRNA) are needed. We aim to investigate the expression of miRNA (miR-21, miR-19a, miR-23a, miR-29a, miR-145, miR-203, miR-155, miR-210, miR-31, and miR-345) in the plasma of 62 Lebanese Stage IV CRC patients and 44 healthy subjects using RT-qPCR, as well as to evaluate their potential for diagnosis of advanced CRC and its liver metastasis using the Receiver Operating Characteristics (ROC) curve. miR-21, miR-145, miR-203, miR-155, miR-210, miR-31, and miR-345 were significantly upregulated in the plasma of surgery naïve CRC patients when compared to healthy individuals. We identified two panels of miRNA that could be used for diagnosis of Stage IV CRC (miR-21 and miR-210) with an area under the curve (AUC) of 0.731 and diagnostic accuracy of $69 \%$ and liver metastasis (miR-210 and miR-203) with an AUC $=0.833$ and diagnostic accuracy of $72 \%$. Panels of specific circulating miRNA, which require further validation, could be potential non-invasive diagnostic biomarkers for CRC and liver metastasis.
\end{abstract}

Keywords: colorectal cancer; microRNA; biomarker; diagnosis; liver metastasis

\section{Introduction}

Colorectal cancer (CRC) is the third most common cancer $(10.2 \%)$ and the second leading cause of cancer death $(9.2 \%)$ in both sexes worldwide, representing a major health burden [1]. In Lebanon, CRC ranked as the fifth most common cancer accounting for $8 \%$ of the newly diagnosed cancer cases over a period of 11 years (2005-2015) [2]. Patients diagnosed with localized and regional CRC (early stage CRC) have a good prognosis with a five-year survival rate reaching 90\%. However, patients with metastatic CRC (Stage IV CRC) have a five-year survival rate of 14\% [3]. Although current screening tests help reduce $C R C$ incidence and mortality, they are characterized by several drawbacks including low sensitivity and specificity, high cost, and invasiveness, which can reduce the patient's compliance [3]. Moreover, liver metastasis is the main cause of mortality in CRC patients [4]. The liver is often the first site of metastatic disease and about $15-25 \%$ of new CRC patients will have liver metastases at the initial time of diagnosis. Although the 5-year overall survival rates after hepatectomy for colorectal cancer metastasis is improved (47-60\% surviving at 5 years), recurrence occurs in $40-75 \%$ of patients after liver resection [5]. As such, it would be essential to find more effective, cheap, and noninvasive biomarkers for the early detection of CRC and continuous monitoring of CRC liver metastasis. 
During the past two decades, research has shed light on microRNA (miRNA) as potential players in the development of several human diseases including cancer. miRNA are small, endogenous, noncoding RNA molecules, approximately 18-25 nucleotides in length, that regulate gene expression at the post-transcriptional level by binding to the $3^{\prime}$-untranslated region (3'-UTR) of mRNAs leading to their translational repression or degradation [6]. Extensive research showed that miRNA are consistently altered in CRC tissues compared to normal ones and they play a pivotal role in its initiation, development, and progression [7]. Notably, miRNA expression is also dysregulated in biological fluids including plasma, serum, saliva, and urine taken from cancer patients compared to those from healthy controls. These circulating molecules are characterized to be stable, reproducible, and consistent among individuals of the same species suggesting that they have the potential to serve as noninvasive diagnostic, prognostic, and therapy predictive biomarkers for several malignancies in general [8] and for CRC in particular [9-11].

Multiple studies have reported the dysregulation of circulating miR-21, miR-19a, miR-23a, miR-29a, miR-145, miR-203, miR-155, miR-210, miR-31, and miR-345 in CRC patients [12-20]. However, most of these studies investigated the miRNA individually on early stage CRC or using heterogeneous CRC population. Therefore, the aim of this study is to determine the expression of these miRNA in the plasma of Lebanese Stage IV CRC patients and to identify panels that could be used for diagnosis of Stage IV CRC in general and liver metastasis in particular.

\section{Results}

\subsection{Characteristics of Study Subjects}

A total of 106 participants were recruited; including 62 Stage IV CRC patients (median age $58 \pm 13.49$ years) and 44 healthy subjects (median age $41.72 \pm 8.97$ years) were recruited in the study (Table 1). Out of the 62 patients with Stage IV CRC, 33 CRC patients gave their blood sample at diagnosis before any bowel resection surgery (surgery naïve), while 15 patients gave their blood sample after a recent bowel resection surgery (postoperative). Fourteen of the patients were previously diagnosed with CRC at an early stage and had undergone bowel resection surgery and were recently diagnosed with Stage IV CRC (recurrent). The majority (61.3\%) of the CRC patients were males, while $40.9 \%$ of the controls were males. All of the healthy subjects $(100 \%)$ were Lebanese as well as most of the CRC patients ( $82 \%$ ). Around $43 \%$ of CRC patients had a family history of cancer and $75.8 \%$ of the CRC patients had liver metastasis. Tumor location was mainly left-sided $(60 \%)$ with right-sided (25\%) and rectal (15\%). As for the most common mutations in CRC patients, $51.9 \%$ had KRAS mutations, $6.1 \%$ had NRAS mutations, and none had BRAF mutation.

\subsection{Circulating miRNA Expression in Surgery Naïve Stage IV CRC Patients Compared to Healthy Subjects}

miRNA expression was measured in the plasma of 33 CRC patients (newly diagnosed and before they had any bowel resection surgery) and compared to their expression in the plasma of 44 healthy subjects. miR-21, miR-145, miR-203, miR-155, miR-210, miR-31, and miR-345 were significantly upregulated in the plasma of surgery naïve CRC patients compared to healthy subjects with a $p$-value of $0.0003,0.0029,0.0103,0.0059,0.0005,0.0135$, and 0.0319 respectively (Figure 1a). On the other hand, miR-19a, miR-29a, and miR-23a were non-significantly dysregulated in the plasma of surgery naïve CRC patients (Figure 1b). 
Table 1. Distribution of Clinicopathological Data for Stage IV CRC patients and healthy subjects. Data were presented as $\mathrm{N}(\%)$ or as Mean \pm SD. BMI: Body Mass Index, Hx: history; mets: metastasis.

\begin{tabular}{|c|c|c|c|c|c|}
\hline Variable & All CRC Patients & Surgery Naïve & Postoperative & Recurrent & Healthy Subjects \\
\hline Sample & $62(58.5)$ & $33(53.2)$ & $15(24.2)$ & $14(22.6)$ & 44 (41.5) \\
\hline Age (years) & $58 \pm 13.49$ & $56.3 \pm 2.2$ & $56.26 \pm 13.86$ & $63.9 \pm 14.25$ & $41.72 \pm 8.97$ \\
\hline$B M I\left(\mathrm{~kg} / \mathrm{m}^{2}\right)$ & $27.17 \pm 6.34$ & $27.6 \pm 6.37$ & $25.1 \pm 7.66$ & $28.37 \pm 4.35$ & $26.39 \pm 0.39$ \\
\hline \multicolumn{6}{|l|}{ Gender } \\
\hline Male & $38(61.3)$ & $21(63.6)$ & $6(40)$ & $11(78.6)$ & $18(40.9)$ \\
\hline Female & $24(38.7)$ & $12(36.4)$ & $9(60)$ & $3(21.4)$ & $26(59.1)$ \\
\hline \multicolumn{6}{|l|}{ Nationality } \\
\hline Lebanese & $50(82)$ & $27(81.8)$ & $12(85.7)$ & $11(78.6)$ & $44(100)$ \\
\hline Iraqi & $8(13.1)$ & $5(15.2)$ & $1(7.1)$ & $2(14.3)$ & \\
\hline Other & $3(4.9)$ & $1(3)$ & $1(7.1)$ & $1(7.1)$ & \\
\hline \multicolumn{6}{|l|}{ Smoking habits } \\
\hline No & $47(75.8)$ & $26(78.8)$ & $11(73.3)$ & $11(78.6)$ & $27(61.4)$ \\
\hline Yes & $15(24.2)$ & $7(21.2)$ & $4(26.7)$ & $3(21.4)$ & $17(38.6)$ \\
\hline \multicolumn{6}{|l|}{ Alcohol intake } \\
\hline No & $48(77.4)$ & $26(78.8)$ & $11(73.3)$ & $11(78.6)$ & $34(81)$ \\
\hline Yes & $14(22.6)$ & $7(21.2)$ & $4(26.7)$ & $3(21.4)$ & $8(19)$ \\
\hline \multicolumn{6}{|c|}{ Family Hx of Cancer } \\
\hline No & $35(57.4)$ & $19(57.6)$ & $7(46.7)$ & $9(64.3)$ & \\
\hline Yes & $26(42.6)$ & $14(42.4)$ & $8(53.3)$ & $4(30.8)$ & \\
\hline \multicolumn{6}{|l|}{ Tumor Sidedness } \\
\hline Left & $36(60)$ & $24(72.7)$ & $6(42.9)$ & $6(42.9)$ & \\
\hline Right & $15(25)$ & $3(9.1)$ & $7(50)$ & $5(35.7)$ & \\
\hline Rectum & $9(15)$ & $5(15.2)$ & $1(7.1)$ & $3(21.4)$ & \\
\hline \multicolumn{6}{|l|}{ Liver Mets } \\
\hline No & $15(24.2)$ & $5(15.2)$ & $4(26.7)$ & $6(42.9)$ & \\
\hline Yes & $47(75.8)$ & $28(84.8)$ & $11(73.3)$ & $8(57.1)$ & \\
\hline \multicolumn{6}{|l|}{ KRAS mutation } \\
\hline No & $26(48.1)$ & $16(53.3)$ & $5(33.3)$ & $6(50)$ & \\
\hline Yes & 28 (51.9) & $14(46.7)$ & $8(53.3)$ & $6(50)$ & \\
\hline \multicolumn{6}{|l|}{ NRAS mutation } \\
\hline No & $46(93.9)$ & $28(93.3)$ & $9(100)$ & $10(90.9)$ & \\
\hline Yes & $3(6.1)$ & $2(6.7)$ & 0 & $1(9.1)$ & \\
\hline \multicolumn{6}{|l|}{ BRAF mutation } \\
\hline No & 49 (100) & $28(100)$ & $9(100)$ & $11(100)$ & \\
\hline Yes & & 0 & 0 & 0 & \\
\hline
\end{tabular}


(a)
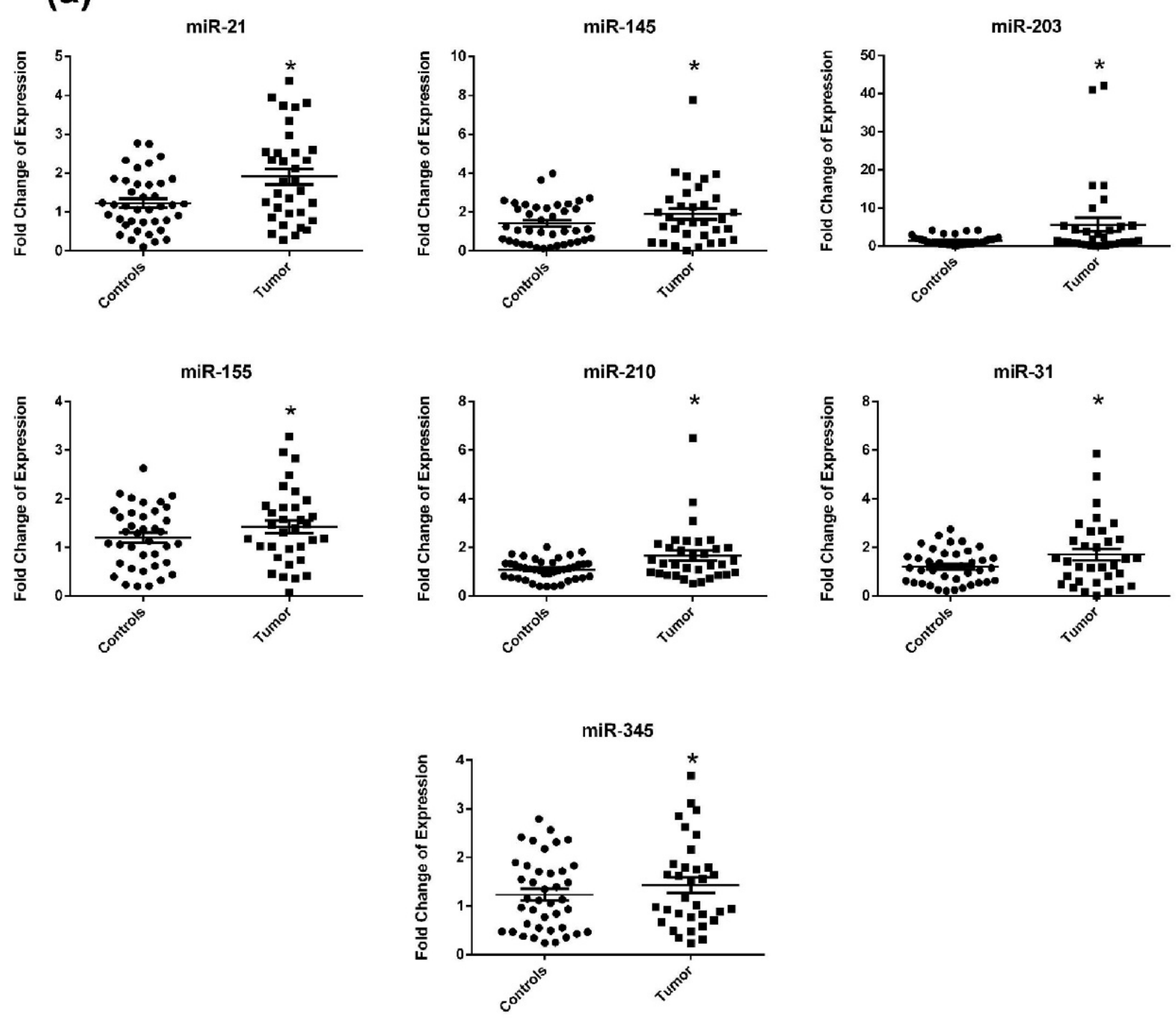

(b)

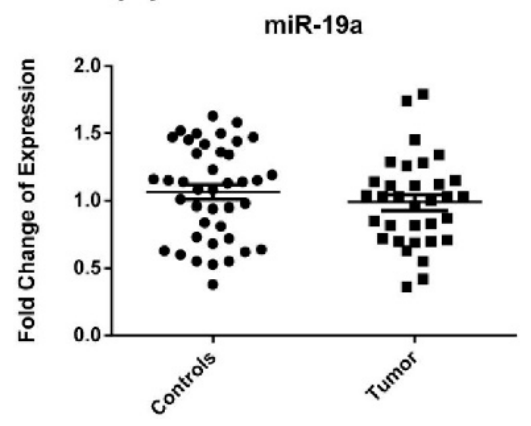

miR-29a

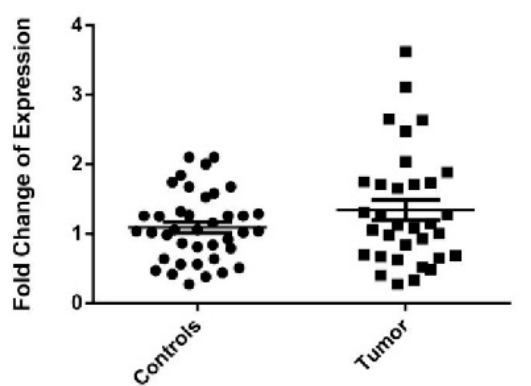

miR-23a

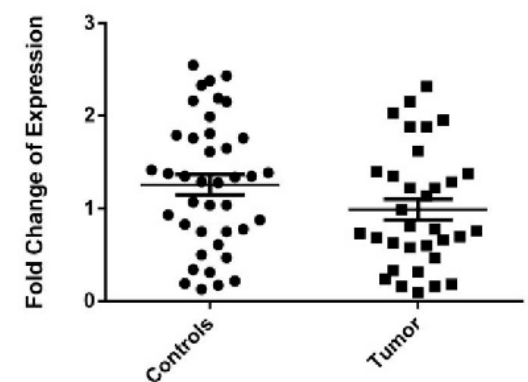

Figure 1. miRNA expression in plasma of newly diagnosed surgery naïve Stage IV colorectal cancer (CRC) patients compared to healthy subjects. (a) Significantly dysregulated miRNA (b) Non-significantly dysregulated miRNA. The dotplots represent the mean (middle line) and the standard error of mean (error bars). miR-16 was used as an endogenous control. * denotes $p$-value $<0.05$ according to Wilcoxon's signed-rank test. 
2.3. Circulating miRNA Expression in Surgery Nä̈ve vs. Postoperative and Recurrent Stage IV CRC Patients

In order to study the effect of bowel surgical resection, we compared miRNA expression in three groups of Stage IV CRC patients whose plasma was taken at diagnosis (surgery naïve $N=33$ ), postoperatively following bowel resection surgery $(N=15)$, or from a recurrent group $(N=14)$ who had already done a bowel resection procedure when diagnosed with early stage CRC but were now newly diagnosed with Stage IV disease. When comparing miRNA expression in plasma of surgery naïve and postoperative CRC patients, miR-21, miR-19a, miR-203, miR-155, miR-31, and miR-345 were significantly upregulated in surgery naïve CRC patients compared to the postoperative ones with respective $p$-value of $0.018,0.0488,0.01147,0.0006,0.044$, and 0.0114 (Figure 2a). Moreover, miR-21, miR-19a, and miR-203 were significantly upregulated in plasma of surgery naïve CRC patients compared to recurrent patients with respective $p$-value of $0.0299,0.0477$ and 0.0051 . Figure $2 \mathrm{~b}$ shows the nonsignificant miRNA dysregulation between the different subgroups. Interestingly, miR-19a was significantly downregulated in postoperative and recurrent CRC patients compared to healthy controls ( $p$-value of 0.012 and 0.0012 respectively) and miR-203 was significantly downregulated in recurrent CRC patients compared to healthy controls with $p$-value of 0.0295 (Figure 2a). Moreover, miR-23a was significantly downregulated in postoperative CRC patients compared to healthy subjects with a $p$-value of 0.0099 (Figure 2b).

\subsection{Diagnostic Accuracy of miRNA for CRC Detection}

In order to evaluate the ability of significantly dysregulated plasma miRNAs to differentiate CRC patients (surgery naïve and recurrent) from healthy subjects, a Receiver Operating Characteristics (ROC) curve was plotted for miRNA with significant AUC area under the curve (AUC) (Figure 3) and the optimal cut-off values, specificity, sensitivity, positive predicted value (PPV), negative predicted value (NPV), and diagnostic accuracy for best diagnostic miRNA were calculated (Table 2). A combined plasma miRNA panel of miR21 and miR-210 had an AUC of $0.731 \pm 0.052$ ( $p$-value of 0.0001 and 95\% CI: 0.63-0.832) and the sensitivity, specificity, and diagnostic accuracy were $87.2 \%, 47.7 \%$, and $69 \%$, respectively. 
(a)
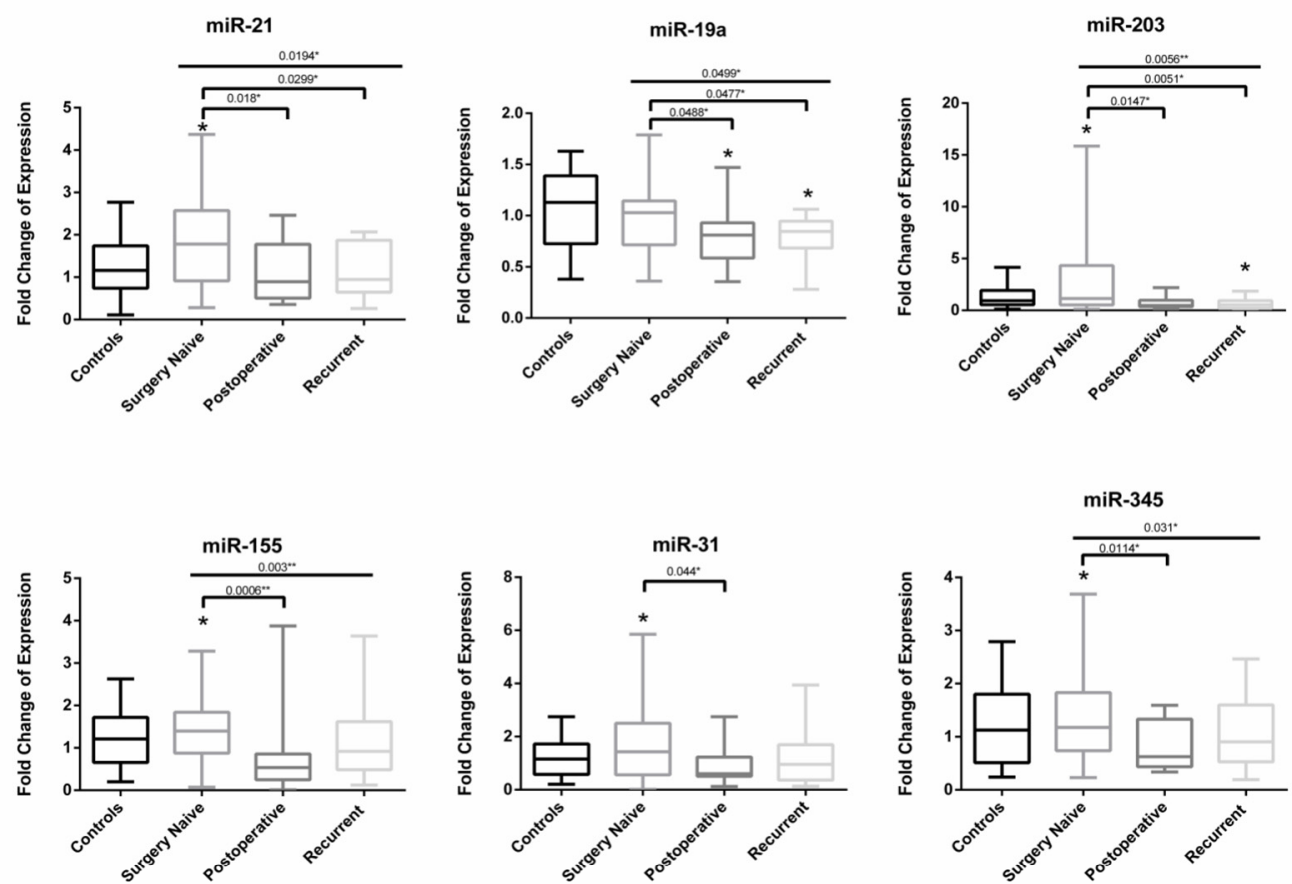

(b)
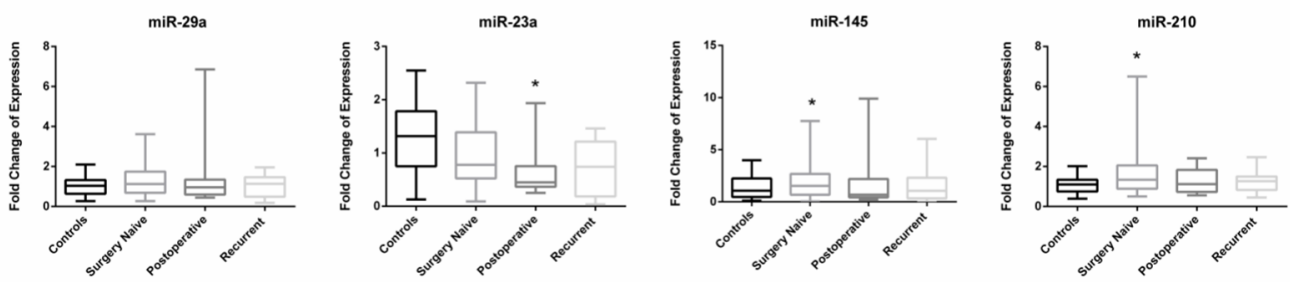

Figure 2. miRNA expression in plasma of surgery naïve Stage IV CRC patients compared to those recently postoperative and those recurrent (meaning newly diagnosed Stage IV CRC previously undergone bowel resection surgery at early stage CRC). (a) Significantly dysregulated miRNA (b) Non-significantly dysregulated miRNA. Whiskers represent minimum and maximum, the top, the bottom, and the band in the box represent the first and third quartile and the median respectively. * above boxplots denotes $p$-value $<0.05$ according to Wilcoxon's signed-rank test. * above line denotes $p$-value $<0.05$ and ** above line denotes $<0.01$ according to Kruskal Wallis test when comparing all subgroups and to Mann-Whitney test when comparing 2 subgroups.
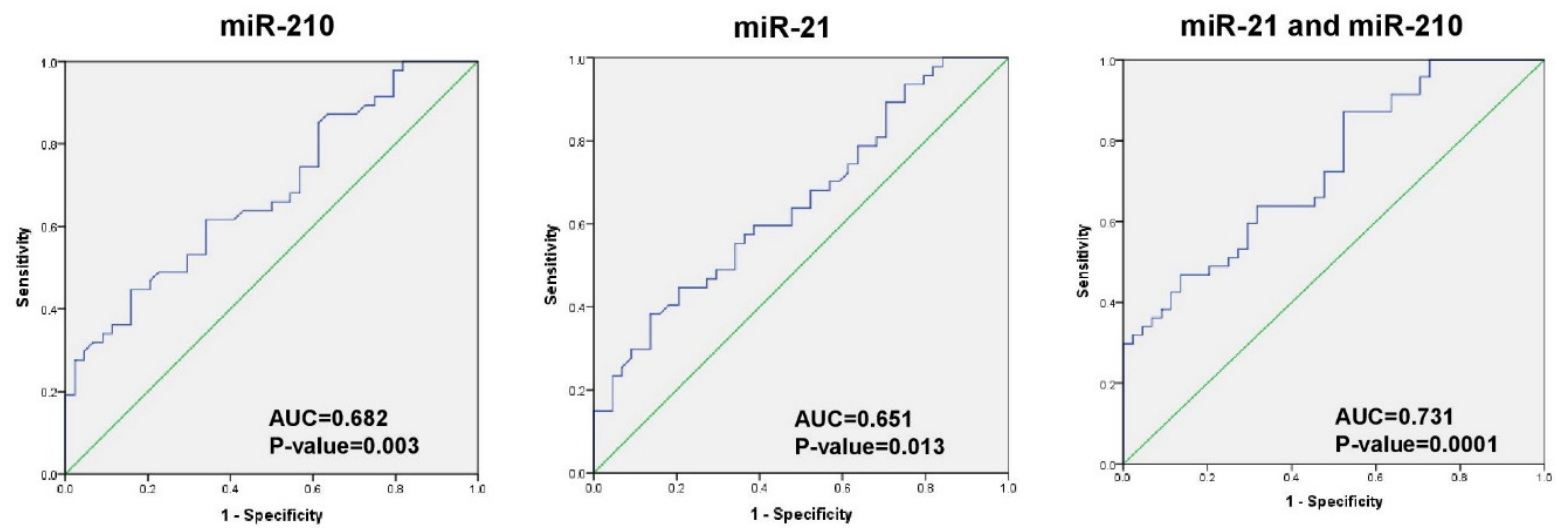

Figure 3. Receiver Operating Characteristics (ROC) curve of miR-210, miR-21 and their combination to differentiate CRC patients from healthy subjects. 
Table 2. Diagnostic parameters to evaluate individual and combined miRNA for diagnosis of CRC patients. AUC: area under the curve, SE: standard error of mean, PPV: positive predicted value, NPV: negative predicted value, and DA: diagnostic accuracy.

\begin{tabular}{|c|c|c|c|c|c|c|c|c|c|c|c|}
\hline miRNA & AUC & SE & $p$-Value & $95 \%$ CI & $\begin{array}{l}\text { Youden's } \\
\text { Index }\end{array}$ & Cut-Off & $\begin{array}{c}\text { Sensitivity } \\
(\%)\end{array}$ & $\begin{array}{c}\text { Specificity } \\
(\%)\end{array}$ & PPV (\%) & NPV (\%) & DA (\%) \\
\hline miR-210 & 0.682 & 0.055 & 0.003 & $\begin{array}{c}0.574- \\
0.79\end{array}$ & 0.288 & 10.46 & 44.7 & 84.1 & 75 & 56 & 62 \\
\hline miR-21 & 0.651 & 0.057 & 0.013 & $\begin{array}{c}0.539- \\
0.76\end{array}$ & 0.247 & 2.81 & 38.3 & 86.4 & 75 & 53 & 59 \\
\hline $\begin{array}{c}\text { miR- } \\
210+21\end{array}$ & 0.731 & 0.052 & 0.0001 & $\begin{array}{l}0.63- \\
0.832\end{array}$ & 0.35 & 0.464 & 87.2 & 47.7 & 65 & 79 & 69 \\
\hline
\end{tabular}

\subsection{Diagnostic Accuracy of miRNA for Liver Metastasis Detection}

None of the miRNA were differentially expressed upon dividing the newly diagnosed Stage IV CRC patients (surgery naïve and recurrent) into subgroups according to age groups (below and above 50 years), body mass index (underweight, normal, overweight, obese), smoking habits, alcohol intake, family history of cancer, tumor sidedness, and KRAS mutation (Data not shown). However, when dividing the CRC patients (surgery naïve and recurrent) into those with and without liver metastasis, miR-19a, miR-210, and miR-203 were significantly dysregulated with respective $p$-values of $0.014,0.001$, and 0.003 (Figure 4a). A combination of plasma miR-210 and miR-203 can distinguish between CRC patients with or without liver metastasis with an AUC of $0.833 \pm 0.063$ ( $p$-value: 0.003 with 95\% CI: 0.622-0.775) (Figure $4 \mathrm{~b}, \mathrm{c}$ ) and a sensitivity, specificity, and diagnostic accuracy of $66.7 \%, 90.9 \%$ and $72 \%$, respectively (Table 3). Notably, as reported in Section 2.2, miR-203 was significantly downregulated in recurrent compared to surgery naïve, while miR-210 was not, so miR-210 alone could be better to differentiate between liver metastasis patients vs. no liver metastasis in the recurrent patients alone.

Upon analyzing whether the studied miRNA could be used to discriminate CRC patients with liver metastasis from healthy subjects and CRC patients with no liver metastasis, miR-210, miR-21, and miR-203 were significantly dysregulated in liver metastatic CRC patients with respective $p$-value of $0.000079,0.033$, and 0.021 . A panel of plasma miR-210, miR-21, and miR-203 had a sensitivity, specificity, and diagnostic accuracy of 55.6\%, 93.9\%, and $71 \%$ with an AUC of 0.798 to identify CRC patients with liver metastasis (Figure 4d). miR-31 had a near borderline significant $p$-value (0.057) when comparing CRC patients with liver metastasis with healthy subjects and CRC patients with no liver metastasis. When adding miR-31 to the panel, it gave higher sensitivity $94.4 \%$, lower specificity of $56.5 \%$ and a diagnostic accuracy of $73 \%$ with an AUC of 0.83 (Figure $4 \mathrm{e}$ ). 


\section{(a)}
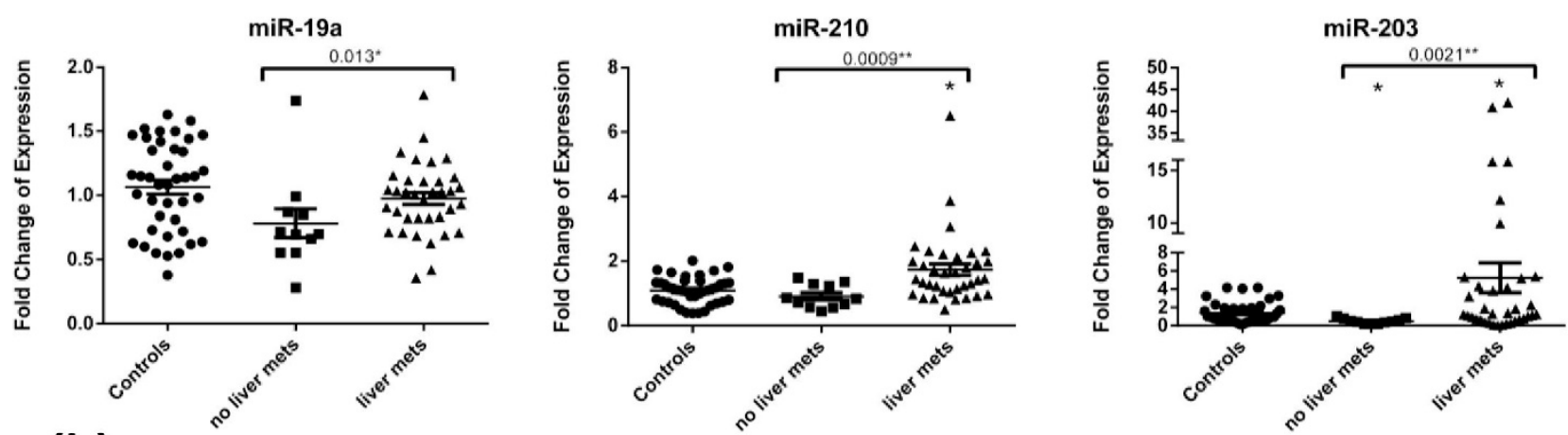

(b) miR-19a

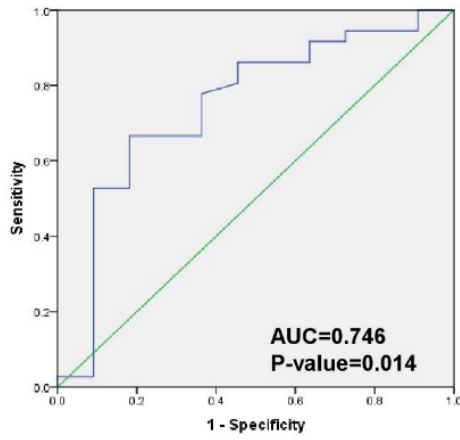

miR-210
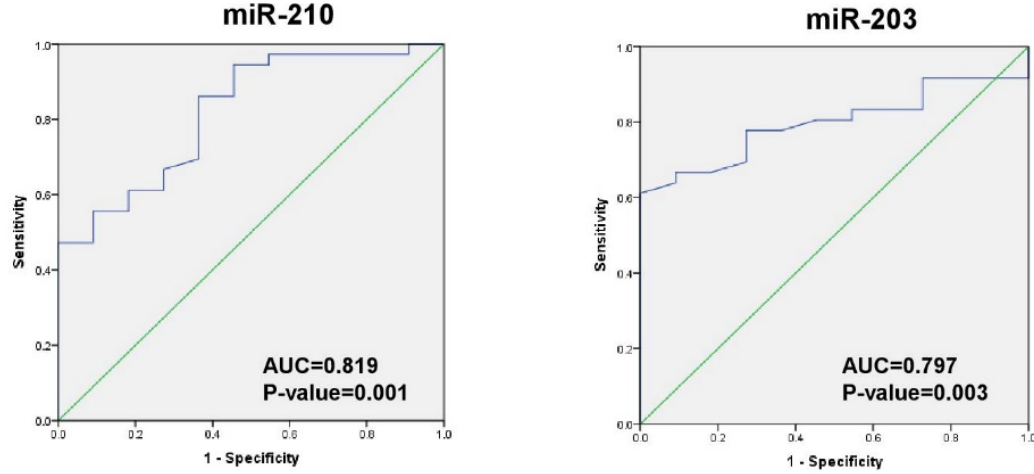

(c) miR-203 and $\mathrm{miR}-210$

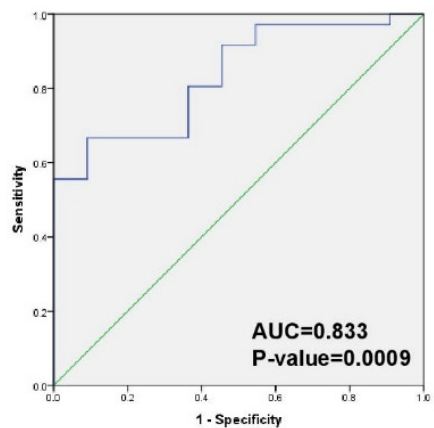

(d)

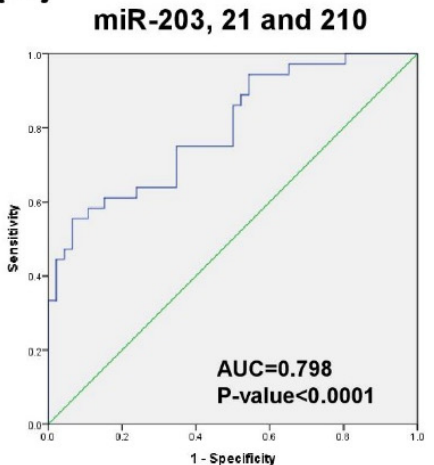

(e) miR-203, 21, 210 and 31

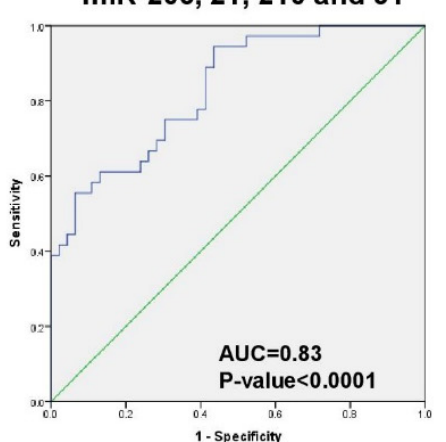

Figure 4. Circulating miRNA for liver metastasis in CRC patients. (a) miR-19a, miR-210, miR-203 expression in CRC patients with liver metastasis vs. metastasis to other sites. The dotplots represent the mean (middle line) and the standard error of mean (error bars). * denotes $p$-value $<0.05$ according to Wilcoxon's signed-rank test. ${ }^{*}$ above line denotes $p$-value $<0.05$ and ** above line denotes $<0.01$ according to Mann-Whitney test. mets: metastasis (b) ROC curve of miR-19a, miR-210, and miR-203 to differentiate CRC patients with liver metastasis from other metastasis. (c) ROC curve of combination miR-210 and miR-203 to differentiate CRC patients with liver metastasis from other metastasis. (d) ROC curve of combination miR-203, miR-21, and miR-210 to differentiate CRC patients with liver metastasis to healthy subjects and those CRC with no liver metastasis. (e) ROC curve of combination of miR-203, miR-21, miR-210, and miR-31 to differentiate CRC patients with liver metastasis to healthy subjects and those CRC with no liver metastasis. 
Table 3. Diagnostic parameters to evaluate individual and combined miRNA for liver metastasis in CRC patients. AUC: area under the curve, SE: standard error of mean, PPV: positive predicted value, NPV: negative predicted value, and DA: diagnostic accuracy.

\begin{tabular}{cccccccccccc}
\hline miRNA & AUC & SE & $\boldsymbol{p}$-Value & $\mathbf{9 5 \%}$ CI & $\begin{array}{c}\text { Youden's } \\
\text { Index }\end{array}$ & Cut-Off & $\begin{array}{c}\text { Sensitivity } \\
\mathbf{( \% )}\end{array}$ & $\begin{array}{c}\text { Specificity } \\
\text { (\%) }\end{array}$ & PPV (\%) & NPV (\%) & DA (\%) \\
\hline$m i R-19 a$ & 0.746 & 0.091 & 0.014 & $0.569-0.924$ & 0.485 & 6.025 & 66.7 & 81.8 & 93 & 45 \\
$m i R-210$ & 0.819 & 0.069 & 0.001 & $0.684-0.955$ & 0.497 & 11.115 & 86.1 & 63.6 & 89 & 58 \\
$\begin{array}{c}m i R-203 \\
\text { miR- }\end{array}$ & 0.797 & 0.063 & 0.003 & $0.673-0.92$ & 0.611 & 15.65 & 61.1 & 100 & 100 & 44 & 70 \\
$210+203$ & 0.833 & 0.063 & 0.0009 & $0.711-0.956$ & 0.576 & 0.838 & 66.7 & 90.9 & 96 & 45 & 72 \\
\hline
\end{tabular}

\section{Discussion}

Several studies have been exploring circulating miRNA as potential biomarkers for CRC diagnosis, prognosis and therapy prediction. However, most of the diagnostic studies were concerned with finding these biomarkers for early stage CRC detection [9]. In this study, we investigated the expression of extensively studied circulating miRNAs in Lebanese Stage IV CRC patients and evaluated their potential to be used as diagnostic biomarkers for advanced CRC and its liver metastasis. Our results showed that miR-21, miR-145, miR-203, miR-155, miR-210, miR-31, and miR-345 were significantly upregulated in the plasma of surgery naïve CRC patients when compared to healthy individuals. However, miR-19a, miR-29a, and miR-23a were non-significantly dysregulated in the plasma of the surgery naïve CRC patients. Moreover, we identified three panels of miRNA that could be used for diagnosis of Stage IV CRC (miR-21 and miR-210) and liver metastasis in CRC \{(miR-210 and miR-203) and (miR-21, 203, 210 and 31).

miR-21 has been shown to be the most upregulated miRNA in hematological and solid tumors including CRC and it acts as an oncomiR [21]. It was reported to promote cell growth and invasion in CRC by targeting PTEN and PDCD4 [22,23]. In CRC, and consistent with our results, miR-21 is upregulated in tissues and in circulation (plasma and serum) compared to healthy controls [24-26]. A recent meta-analysis conducted on 18 studies including 1129 blood specimens of CRC patients and 951 control specimens has reported that circulating miR-21 has a potential diagnostic value with moderate sensitivity $77 \%$ and good specificity $83 \%$ for CRC [27].

miR-210, a hypoxia-regulated miRNA exhibits oncogenic properties in most cancers, where it mediates cell proliferation, migration, invasion, and clonogenicity [28]. It has been identified along with eight other miRNA as potentially useful diagnostic biomarkers in CRC tissues [29]. Many reported its potential diagnostic value as it is upregulated in the serum of CRC patients similarly to our data in plasma $[16,26,30]$.

As for miR-203, its role and expression in CRC tissues is controversial [31,32]. It acts as a tumor suppressor in CRC that inhibits proliferation, migration, and invasion [33] and plays a role in metastasis acting as a signaling molecule in exosomes between tumors and monocytes in metastatic CRC patients [34]. miR-203 was significantly upregulated in plasma of our Stage IV CRC cases similarly to what is reported in plasma and serum of previous studies [35,36]. Its expression is even higher in Stage III-IV CRC when compared to Stage I-II CRC [35]. A meta-analysis evaluated the diagnostic value of miR-203 for the diagnosis of CRC by pooling the data from nine studies and reported $83 \%$ sensitivity and $80 \%$ specificity [37]. However, miR-203 was found to be downregulated in serum of CRC patients (majority of Stage II and III) compared to controls and was considered with five other serum miRNAs (miR-21, let-7g, miR-31, miR-92, and miR-181b) to distinguish CRC from controls [38].

miR-31 acts as a promoter of cell proliferation, invasion, and migration in vitro and tumorigenesis and metastasis in CRC [39]. It is reported to be overexpressed in CRC tissues compared to normal tissues [40]. Similar to our results in plasma, it is also upregulated in serum of CRC patients [41] where it exhibits along with miR-146a-5p, and miR-148a-3p strong diagnostic ability [42]. High levels of miR-31 were found in plasma of CRC patients 
with lymph node metastasis compared to patients without lymph node metastasis or healthy individuals [43]. However, serum miR-31 was reported to be downregulated in another study with a majority of Stage II and III CRC patients [38].

Moreover, we found miR-145, miR-155 and miR-345 to be significantly upregulated in the plasma of surgery naïve CRC patients. miR-145 has been reported to be downregulated in CRC tissues and to act as a tumor suppressor that suppresses proliferation, metastasis, and EMT in CRC [44,45]. The upregulation of miR-145 detected in our samples is not in accordance with the literature. Several studies reported its downregulation in the plasma/serum of CRC patients of different ethnicities when compared to healthy controls and shed its association with clinical stage [14,36,46-49]. miR-155 is reported to be upregulated in colon cancer tissues compared to normal ones and to be involved in the invasion of colorectal cancer SW-480 cells by regulating the Wnt/ $\beta$-catenin pathway [18,50]. Our data has shown that miR-155 was significantly upregulated in plasma of surgery naïve Stage IV CRC patients compared to control. This is in accordance with Lv et al. who reported its upregulation in the serum of CRC patients particularly highest in Stage IV when compared to matched healthy controls and its ability to distinguish between these two groups [18]. However, another study showed that miR-155 was downregulated in the serum of patients with colonic and rectal cancer when compared to controls, while being higher in rectal than in colonic cancer [51]. On the other hand, miR-345 has not been studied for CRC diagnosis. It has been reported to be downregulated in CRC tissues with a potential role in suppressing cell proliferation and invasion [52]. High circulating serum miR-345 was found to correlated with unfavorable preoperative chemoradiotherapy response and poor locoregional control in locally advanced rectal cancer [20] and its high expression in blood in metastatic CRC was associated with worse outcome in non-KRAS mutant patients treated with 3rd Line Cetuximab and Irinotecan [53]. However, in our study, it was upregulated in the plasma of surgery naïve Stage IV CRC. As for the other potential oncomiRs in CRC (miR-19a [54], miR-29a [55], and miR-23a [56]) we obtained nonsignificant dysregulation in plasma of Stage IV CRC patients which also contrasts their upregulation in CRC blood/plasma/serum reported in the literature [12,13,24,46,57,58].

Our data showed that miR-19a, miR-210, and miR-203 could distinguish between CRC patients with liver metastasis and those with other metastasis. Increase in exosomal miR-19a in the serum of CRC patients was associated with liver metastasis compared with the low expression group [59]. miR-19a was reported to have a role in invasion and metastasis in vitro by inhibiting Transglutaminase-2 (TG2), a critical cross-linking enzyme in the extracellular matrix (ECM) and tumor microenvironment [60,61]. miR-203 levels have been shown to be upregulated in liver metastasis compared to matched primary CRC tissues. In addition, high serum miR-203 expression was significantly associated with liver metastasis and other metastasis. Serum miR-203 expression significantly discriminated CRC patients with liver metastasis with an AUC $=0.719$, sensitivity $(61.54 \%)$, and specificity $(84.18 \%)$ in cohort of 24 healthy controls and 186 preoperative CRC samples and an AUC $=0.690$, sensitivity $(91.67 \%)$, and specificity $(46.97 \%)$ in the validation cohort composed of 144 preoperative CRC samples [15]. Another study reported that high miR-203 expression group correlated with higher incidence of distant metastasis including liver metastasis $(p<0.01)$ as compared to the low expression group. In addition, overexpressing miR-203 in a xenograft mice model promoted more liver metastasis [34]. As for miR-210, microarray analysis identified its upregulation in liver metastasis tissues samples compared to primary CRC tumor tissues [62]. This was also validated by another study that used real time PCR and found out the overexpression of miR-210 in liver metastases compared to primary tumors is associated with lower survival [63]. Recent studies revealed that serum miR-210 levels has diagnostic value to discriminate patients with metastatic tumors to patients with primary hepatocellular carcinoma [64] and in predicting the recurrence and prognosis of CRC hepatic metastasis [65]. Overall, these results show that miR-19a, miR-210, and miR-203 might play a promising role as non-invasive liver metastasis-prognostic biomarkers in patients with metastatic CRC. Interestingly, high levels of miR-21 and miR-31 are 
present in tissue samples of liver metastasis [66,67]. miR-21 in plasma derived exosomes are positively correlated with liver metastasis in CRC patients [68,69]. Notably, serum miR-21 was identified as CRC liver metastasis-associated miRNA when evaluated in 116 consecutive localized, 72 synchronous liver-metastatic CRC and 36 other organ-metastatic CRC by real-time PCR [70]. These two miRNAs were identified as a panel with miR-210, miR-203 for detection of liver metastasis (in CRC) compared to no liver metastasis (in CRC and healthy).

Some limitations to the use of miRNAs as biomarkers lie in the fact that CRC itself is a heterogeneous disease and the expression of miRNAs vary significantly within tumor population. Also, the lack of consensus on suitable small RNA reference genes to quantify circulating miRNA levels makes establishment of global cut-off value difficult. Finally, some miRNAs are highly expressed in the blood cells, and levels of circulating miRNAs can be significantly altered by hemolysis. Thus, the standardization of protocols and methodologies, including sample storage, RNA extraction, and quantification of circulating miRNAs, are necessary to improve the biomarker potential of miRNAs.

\section{Materials and Methods}

\subsection{Specimen Collection}

After Institutional Review Board (IRB) approval of the study (BIO-2018-0041), sixtytwo CRC patients and 44 healthy controls were recruited from the American University of Beirut Medical Center between May 2018 and September 2020. Written informed consent was obtained from all participants. CRC patients were all newly diagnosed Stage IV that were confirmed by biopsy or radiological imaging. None of the patients has a history of autoimmune or inflammatory bowel diseases and none had undergone chemotherapy before sample collection. The healthy controls had no history of cancer or autoimmune and inflammatory bowel diseases. All patient clinicopathological characteristics were collected from their medical records. Whole blood was collected from each participant into EDTA tube for miRNA analysis. Plasma was subsequently isolated by double centrifugation steps and then stored at $-80^{\circ} \mathrm{C}$ until further step.

\subsection{Total RNA Extraction}

Total RNA was extracted from $250 \mu \mathrm{L}$ plasma using Plasma/Serum Circulating and Exosomal RNA Purification Kit (Norgen Biotek Corp., Thorold, ON, Canada) according to the manufacturer's instructions. Assessment of RNA concentration and quality was done using DeNovix DS-11 FX spectrophotometer (Wilmington, DE, USA). The total RNA samples were stored at $-80^{\circ} \mathrm{C}$ until analysis.

\section{3. miRNA Expression Using Reverse Transcription Quantitative Real Time Polymerase Chain} Reaction (RT-qPCR)

For reverse transcription and RT-qPCR, validated primers and probes from TaqMan ${ }^{\circledR}$ microRNA Assays Kit (Applied Biosystems, Waltham, MA, USA) were used for hsamiR-16, hsa-miR-21, hsa-miR-19a, hsa-miR-29a, hsa-miR-23a, hsa-miR-145, hsa-miR-203, hsa-miR-155, hsa-miR-210, hsa-miR-31, and hsa-miR-345. cDNA was synthesized for the miRNA of interest starting from $10 \mathrm{ng}$ of extracted RNA using TaqMan ${ }^{\circledR}$ MicroRNA Reverse Transcription Kit (Applied Biosystems, Waltham, MA, USA) according to the manufacturer's instructions. RT-qPCR was then carried out in duplicates for each sample using 2x TaqMan ${ }^{\circledR}$ Universal Master Mix with no Amperase Uracil N-glycosylase (UNG) (Applied Biosystems, Waltham, MA, USA) as previously described [71]. RT-qPCR was performed using BioRad CFX96 Real Time System, C1000 Thermal Cycler (Hercules, CA, USA). The cycling conditions were $10 \mathrm{~min}$ at $95^{\circ} \mathrm{C}$ then 40 cycles of: $15 \mathrm{~s}$ at $95^{\circ} \mathrm{C}$ and $60 \mathrm{~s}$ at $60{ }^{\circ} \mathrm{C}$. The fold change of miRNA expression was calculated using the $\Delta \Delta \mathrm{Ct}$ equation where miR-16 is endogenous control and compared to healthy controls. 


\subsection{Statistical Analysis}

All statistical analyses were performed using SPSS version 22 (Armonk, NY, USA) and GraphPad Prism 6 software (San Diego, CA, USA). Baseline characteristics were presented as mean \pm standard deviation (SD) for continuous data and as number (percentages) for categorical parameters. Wilcoxon signed rank test was used as a non-parametric one sample test when comparing the fold change of expression of the miRNA to that of healthy subject considered as 1. Mann-Whitney $U$ and Kruskal-Wallis tests were applied to detect any significant dysregulation of the miRNA within two or more clinicopathological subgroups. Diagnostic accuracy of candidate miRNAs or their combinations was assessed by Receiver Operating Characteristic (ROC) curves analysis using $\Delta \mathrm{Ct}$ values or predicted probability calculated from binary logistic regression analysis. In order to identify the best cut-off, sensitivity and specificity for each miRNA, Youden's index was calculated. $p$-values less than 0.05 were considered statistically significant.

\section{Conclusions}

In conclusion, this is the first study to report circulating miRNA expression in Lebanese Stage IV CRC patients with identification of miRNA panels that could distinguish surgery naïve CRC patients from healthy controls and that could differentiate between CRC with liver metastasis and those with other metastasis or healthy controls. Taken together, our data suggests that circulating miRNA could be potential non-invasive diagnostic biomarkers for CRC and liver metastasis. Further validations from larger, independent cohorts are needed and comparability with other routine tests are required.

Author Contributions: For Conceptualization, Supervision and Funding Acquisition, R.R.N. and S.N.T.; Methodology, F.J.N.; Software and Formal Analysis, F.J.N., M.M.I.; Validation, F.J.N. and Z.S.M.; Investigation, F.J.N., M.M.I., Z.S.M., R.H., R.E.H., F.K.; Resources, F.J.N.; Data Curation, F.J.N.; Writing一Original Draft Preparation, F.J.N., Z.S.M., R.R.N., S.N.T.; Writing-Review \& Editing, D.M., A.S., R.R.N. and S.N.T.; Visualization, F.J.N.; Project Administration, F.J.N., R.B. All authors have read and agreed to the published version of the manuscript.

Funding: This research was funded by the Medical Practice Plan (MPP) at Faculty of Medicine, AUB.

Institutional Review Board Statement: The study was conducted according to the guidelines of the Declaration of Helsinki and approved by the Institutional Review Board of American University of Beirut (protocol code: BIO-2018-0041 and date of approval: 18 April 2018).

Informed Consent Statement: Informed consent was obtained from all subjects involved in the study. Written informed consent has been obtained from the patients to publish this paper.

Data Availability Statement: The data presented in this study are available on request from the corresponding author. The data are not publicly available due to patient data privacy and ongoing research.

Acknowledgments: We would like to thank first the CRC patients and the healthy subjects for their participation and DTS core facilities and the administrative staff and nurses at Naef K. Basile Cancer Center for their support.

Conflicts of Interest: The authors declare no conflict of interest.

\section{References}

1. Bray, F.; Ferlay, J.; Soerjomataram, I.; Siegel, R.L.; Torre, L.A.; Jemal, A. Global cancer statistics 2018: GLOBOCAN estimates of incidence and mortality worldwide for 36 cancers in 185 countries. CA Cancer J. Clin. 2018, 68, 394-424. [CrossRef] [PubMed]

2. Khachfe, H.H.; Salhab, H.A.; Fares, M.Y.; Khachfe, H.M. Probing the Colorectal Cancer Incidence in Lebanon: An 11-Year Epidemiological Study. J. Gastrointest. Cancer 2020, 51, 805-812. [CrossRef]

3. Howlader, N.; Noone, A.M.K.M.; Miller, D.; Brest, A.; Yu, M.; Ruhl, J.; Tatalovich, Z.; Mariotto, A.; Lewis, D.R.; Chen, H.S.; et al. SEER Cancer Statistics Review 1975-2016; National Cancer Institute: Bethesda, MD, USA, 2018.

4. Misiakos, P.E.; Karidis, N.P.; Kouraklis, G. Current treatment for colorectal liver metastases. World J. Gastroenterol. 2011, 17, 4067-4075. [CrossRef] [PubMed]

5. Kow, A.W.C. Hepatic metastasis from colorectal cancer. J. Gastrointest. Oncol. 2019, 10, 1274-1298. [CrossRef] [PubMed] 
6. Bartel, D.P. MicroRNAs: Genomics, biogenesis, mechanism, and function. Cell 2004, 116, 281-297. [CrossRef]

7. Schetter, A.J.; Okayama, H.; Harris, C.C. The Role of MicroRNAs in Colorectal Cancer. Cancer J. 2012, 18, 244-252. [CrossRef]

8. Cui, M.; Wang, H.; Yao, X.; Zhang, D.; Xie, Y.; Cui, R.; Zhang, X. Circulating MicroRNAs in Cancer: Potential and Challenge. Front. Genet. 2019, 10, 626. [CrossRef]

9. Rapado-González, Ó.; Álvarez-Castro, A.; López-López, R.; Iglesias-Canle, J.; Suárez-Cunqueiro, M.M.; Muinelo-Romay, L. Circulating microRNAs as Promising Biomarkers in Colorectal Cancer. Cancers 2019, 11, 898. [CrossRef] [PubMed]

10. Nasr, R.; Hammoud, M.S.; Nassar, F.; Mukherji, D.; Shamseddine, A.I.; Temraz, S. Inflammatory Markers and MicroRNAs: The Backstage Actors Influencing Prognosis in Colorectal Cancer Patients. Int. J. Mol. Sci. 2018, 19, 1867. [CrossRef]

11. Mitchell, P.S.; Parkin, R.K.; Kroh, E.M.; Fritz, B.R.; Wyman, S.K.; Pogosova-Agadjanyan, E.L.; Peterson, A.; Noteboom, J.; O’Briant, K.C.; Allen, A.; et al. Circulating microRNAs as stable blood-based markers for cancer detection. Proc. Natl. Acad. Sci. USA 2008, 105, 10513-10518. [CrossRef]

12. Marcuello, M.; Duran-Sanchon, S.; Moreno, L.; Lozano, J.J.; Bujanda, L.; Castells, A.; Gironella, M. Analysis of A 6-Mirna Signature in Serum from Colorectal Cancer Screening Participants as Non-Invasive Biomarkers for Advanced Adenoma and Colorectal Cancer Detection. Cancers 2019, 11, 1542. [CrossRef]

13. Yamada, A.; Horimatsu, T.; Okugawa, Y.; Nishida, N.; Honjo, H.; Ida, H.; Kou, T.; Kusaka, T.; Sasaki, Y.; Yagi, M.; et al. Serum miR-21, miR-29a, and miR-125b Are Promising Biomarkers for the Early Detection of Colorectal Neoplasia. Clin. Cancer Res. 2015, 21, 4234-4242. [CrossRef]

14. Ramzy, I.; Hasaballah, M.; Marzaban, R.; Shaker, O.; Soliman, Z.A. Evaluation of microRNAs-29a, 92a and 145 in colorectal carcinoma as candidate diagnostic markers: An Egyptian pilot study. Clin. Res. Hepatol. Gastroenterol. 2015, 39, 508-515. [CrossRef]

15. Hur, K.; Toiyama, Y.; Okugawa, Y.; Ide, S.; Imaoka, H.; Boland, C.R.; Goel, A. Circulating microRNA-203 predicts prognosis and metastasis in human colorectal cancer. Gut 2017, 66, 654-665. [CrossRef]

16. Wang, W.; Qu, A.; Liu, W.; Liu, Y.; Zheng, G.; Du, L.; Zhang, X.; Yang, Y.; Wang, C.; Chen, X. Circulating miR-210 as a diagnostic and prognostic biomarker for colorectal cancer. Eur. J. Cancer Care 2016, 26, e12448. [CrossRef]

17. Yong, F.L.; Law, C.W.; Wang, C.W. Potentiality of a triple microRNA classifier: miR-193a-3p, miR-23a and miR-338-5p for early detection of colorectal cancer. BMC Cancer 2013, 13, 280. [CrossRef]

18. Lv, Z.-C.; Fan, Y.-S.; Chen, H.-B.; Zhao, D.-W. Investigation of microRNA-155 as a serum diagnostic and prognostic biomarker for colorectal cancer. Tumor Biol. 2015, 36, 1619-1625. [CrossRef] [PubMed]

19. Yuan, Z.; Baker, K.; Redman, M.W.; Wang, L.; Adams, S.V.; Yu, M.; Dickinson, B.; Makar, K.; Ulrich, N.; Böhm, J.; et al. Dynamic plasma microRNAs are biomarkers for prognosis and early detection of recurrence in colorectal cancer. Br. J. Cancer 2017, 117, 1202-1210. [CrossRef] [PubMed]

20. Yu, J.; Li, N.; Wang, X.; Ren, H.; Wang, W.; Wang, S.; Song, Y.; Liu, Y.; Li, Y.; Zhou, X.; et al. Circulating serum microRNA345 correlates with unfavorable pathological response to preoperative chemoradiotherapy in locally advanced rectal cancer. Oncotarget 2016, 7, 64233-64243. [CrossRef] [PubMed]

21. Feng, Y.-H.; Tsao, C.-J. Emerging role of microRNA-21 in cancer. Biomed. Rep. 2016, 5, 395-402. [CrossRef]

22. Wu, Y.; Song, Y.; Xiong, Y.; Wang, X.; Xu, K.; Han, B.; Bai, Y.; Liming, Z.; Zhang, Y.; Zhou, L. MicroRNA-21 (Mir-21) Promotes Cell Growth and Invasion by Repressing Tumor Suppressor PTEN in Colorectal Cancer. Cell. Physiol. Biochem. 2017, 43, 945-958. [CrossRef]

23. Asangani, I.A.; Rasheed, S.A.K.; Nikolova, D.A.; Leupold, J.H.; Colburn, N.H.; Post, S.; Allgayer, H. MicroRNA-21 (miR-21) post-transcriptionally downregulates tumor suppressor Pdcd4 and stimulates invasion, intravasation and metastasis in colorectal cancer. Oncogene 2007, 27, 2128-2136. [CrossRef] [PubMed]

24. Farouk, S.; Khairy, A.; Salem, A.M.; Soliman, A.F.; El Din, N.G.B. Differential Expression of miR-21, miR-23a, and miR-27a, and Their Diagnostic Significance in Egyptian Colorectal Cancer Patients. Genet. Test. Mol. Biomark. 2020, 24, 825-834. [CrossRef]

25. Kanaan, Z.; Rai, S.N.; Eichenberger, M.R.; Roberts, H.; Keskey, B.; Pan, J.; Galandiuk, S. Plasma miR-21: A potential diagnostic marker of colorectal cancer. Ann. Surg. 2012, 256, 544-551. [CrossRef] [PubMed]

26. Sabry, D.; El-Deek, S.E.M.; Maher, M.; El-Baz, M.A.H.; El-Bader, H.M.; Amer, E.; Hassan, E.A.; Fathy, W.; El-Deek, H.E.M. Role of miRNA-210, miRNA-21 and miRNA-126 as diagnostic biomarkers in colorectal carcinoma: Impact of HIF-1 $\alpha$-VEGF signaling pathway. Mol. Cell. Biochem. 2019, 454, 177-189. [CrossRef] [PubMed]

27. Liu, T.; Liu, D.; Guan, S.; Dong, M. Diagnostic role of circulating MiR-21 in colorectal cancer: A update meta-analysis. Ann. Med. 2021, 53, 87-102. [CrossRef]

28. Bavelloni, A.; Ramazzotti, G.; Poli, A.; Piazzi, M.; Focaccia, E.; Blalock, W.; Faenza, I. MiRNA-210: A Current Overview. Anticancer Res. 2017, 37, 6511-6521. [CrossRef]

29. Di, Z.; Di, M.; Fu, W.; Tang, Q.; Liu, Y.; Lei, P.; Gu, X.; Liu, T.; Sun, M. Integrated Analysis Identifies a Nine-microRNA Signature Biomarker for Diagnosis and Prognosis in Colorectal Cancer. Front. Genet. 2020, 11, 192. [CrossRef]

30. Li, G.; Wang, Q.; Li, Z.; Shen, Y. Serum miR-21 and miR-210 as promising non-invasive biomarkers for the diagnosis and prognosis of colorectal cancer. Rev. Esp. Enferm. Dig. 2020, 112, 832-837. [CrossRef]

31. Chiang, Y.; Song, Y.; Wang, Z.; Chen, Y.; Yue, Z.; Xu, H.; Xing, C.; Liu, Z. Aberrant Expression of miR-203 and Its Clinical Significance in Gastric and Colorectal Cancers. J. Gastrointest. Surg. 2010, 15, 63-70. [CrossRef] 
32. Bovell, L.C.; Shanmugam, C.; Putcha, B.D.K.; Katkoori, V.R.; Zhang, B.; Bae, S.; Singh, K.P.; Grizzle, W.E.; Manne, U. The Prognostic Value of MicroRNAs Varies with Patient Race/Ethnicity and Stage of Colorectal Cancer. Clin. Cancer Res. 2013, 19, 3955-3965. [CrossRef]

33. Deng, B.; Wang, B.; Fang, J.; Zhu, X.; Cao, Z.; Lin, Q.; Zhou, L.; Sun, X. MiRNA-203 suppresses cell proliferation, migration and invasion in colorectal cancer via targeting of EIF5A. Sci. Rep. 2016, 6, 28301. [CrossRef] [PubMed]

34. Takano, Y.; Masuda, T.; Iinuma, H.; Yamaguchi, R.; Sato, K.; Tobo, T.; Hirata, H.; Kuroda, Y.; Nambara, S.; Hayashi, N.; et al. Circulating exosomal microRNA-203 is associated with metastasis possibly via inducing tumor-associated macrophages in colorectal cancer. Oncotarget 2017, 8, 78598-78613. [CrossRef] [PubMed]

35. Sun, Y.; Liu, Y.; Cogdell, D.; Calin, G.A.; Sun, B.; Kopetz, S.; Hamilton, S.R.; Zhang, W. Examining plasma microRNA markers for colorectal cancer at different stages. Oncotarget 2016, 7, 11434-11449. [CrossRef]

36. Huang, G.; Wei, B.; Chen, Z.; Wang, J.; Zhao, L.; Peng, X.; Liu, K.; Lai, Y.; Ni, L. Identification of a four-microRNA panel in serum as promising biomarker for colorectal carcinoma detection. Biomark. Med. 2020, 14, 749-760. [CrossRef]

37. Ye, H.; Hao, H.; Wang, J.; Chen, R.; Huang, Z. miR-203 as a novel biomarker for the diagnosis and prognosis of colorectal cancer: A systematic review and meta-analysis. Oncotarget Ther. 2017, 10, 3685-3696. [CrossRef] [PubMed]

38. Wang, J.; Huang, S.-K.; Zhao, M.; Yang, M.; Zhong, J.-L.; Gu, Y.-Y.; Peng, H.; Che, Y.-Q.; Huang, C.-Z. Identification of a Circulating MicroRNA Signature for Colorectal Cancer Detection. PLoS ONE 2014, 9, e87451. [CrossRef]

39. Yu, T.; Ma, P.; Wu, D.; Shu, Y.; Gao, W. Functions and mechanisms of microRNA-31 in human cancers. Biomed. Pharm. 2018, 108, 1162-1169. [CrossRef]

40. Mi, B.; Li, Q.; Li, T.; Liu, G.; Sai, J. High miR-31-5p expression promotes colon adenocarcinoma progression by targeting TNS. Aging 2020, 12, 7480-7490. [CrossRef]

41. Wang, Y.-N.; Chen, Z.-H.; Chen, W. Novel circulating microRNAs expression profile in colon cancer: A pilot study. Eur. J. Med. Res. 2017, 22, 1-11. [CrossRef]

42. Peng, X.; Wang, J.; Zhang, C.; Liu, K.; Zhao, L.; Chen, X.; Huang, G.; Lai, Y. A three-miRNA panel in serum as a noninvasive biomarker for colorectal cancer detection. Int. J. Biol. Markers 2020, 35, 74-82. [CrossRef] [PubMed]

43. Zhang, W.-W.; Ming, X.-L.; Rong, Y.; Huang, C.-Q.; Weng, H.; Chen, H.; Bian, J.-M.; Wang, F.-B. Diagnostic Value Investigation and Bioinformatics Analysis of miR-31 in Patients with Lymph Node Metastasis of Colorectal Cancer. Anal. Cell. Pathol. 2019, 2019, 9740475. [CrossRef]

44. Niu, Y.; Zhang, J.; Tong, Y.; Li, J.; Liu, B. miR-145-5p restrained cell growth, invasion, migration and tumorigenesis via modulating RHBDD1 in colorectal cancer via the EGFR-associated signaling pathway. Int. J. Biochem. Cell Biol. 2019, 117, 105641. [CrossRef]

45. Chen, Q.; Zhou, L.; Ye, X.; Tao, M.; Wu, J. miR-145-5p suppresses proliferation, metastasis and EMT of colorectal cancer by targeting CDCA. Pathol. Res. Pract. 2020, 216, 152872. [CrossRef]

46. Maminezhad, H.; Ghanadian, S.; Pakravan, K.; Razmara, E.; Rouhollah, F.; Mossahebi-Mohammadi, M.; Babashah, S. A panel of six-circulating miRNA signature in serum and its potential diagnostic value in colorectal cancer. Life Sci. 2020, $258,118226$. [CrossRef]

47. Luo, X.; Wu, Y.; Ji, M.; Zhang, S. Combined Plasma MicroRNA and Fecal Occult Blood Tests in Early Detection of Colorectal Cancer. Clin. Lab. 2019, 65, 65. [CrossRef]

48. Eslamizadeh, S.; Heidari, M.; Agah, S.; Faghihloo, E.; Ghazi, H.; Mirzaei, A.; Akbari, A. The Role of MicroRNA Signature as Diagnostic Biomarkers in Different Clinical Stages of Colorectal Cancer. Cell J. 2018, 20, 220-230.

49. Liu, Q.; Yang, W.; Luo, Y.; Hu, S.; Zhu, L. Correlation between miR-21 and miR-145 and the incidence and prognosis of colorectal cancer. JBUON 2018, 23, 29-35. [PubMed]

50. Liu, N.; Jiang, F.; Han, X.-Y.; Li, M.; Chen, W.-J.; Liu, Q.-C.; Liao, C.-X.; Lv, Y.-F. MiRNA-155 promotes the invasion of colorectal cancer SW-480 cells through regulating the Wnt/ $\beta$-catenin. Eur. Rev. Med. Pharmacol. Sci. 2018, 22, 101-109.

51. Orosz, E.; Kiss, I.; Gyöngyi, Z.; Varjas, T. Expression of Circulating miR-155, miR-21, miR-221, miR-30a, miR-34a and miR-29a: Comparison of Colonic and Rectal Cancer. In Vivo 2018, 32, 1333-1337. [CrossRef] [PubMed]

52. Tang, J.-T.; Wang, J.-L.; Du, W.; Hong, J.; Zhao, S.-L.; Wang, Y.-C.; Xiong, H.; Chen, H.-M.; Fang, J.-Y. MicroRNA 345, a methylationsensitive microRNA is involved in cell proliferation and invasion in human colorectal cancer. Carcinogenesis 2011, 32, 1207-1215. [CrossRef]

53. Schou, J.; Rossi, S.; Jensen, B.V.; Nielsen, D.L.; Pfeiffer, P.; Høgdall, E.V.; Yilmaz, M.; Tejpar, S.; Delorenzi, M.; Kruhøffer, M.; et al. miR-345 in Metastatic Colorectal Cancer: A Non-Invasive Biomarker for Clinical Outcome in Non-KRAS Mutant Patients Treated with 3rd Line Cetuximab and Irinotecan. PLOS ONE 2014, 9, e99886. [CrossRef]

54. Liu, Y.; Liu, R.; Yang, F.; Cheng, R.; Chen, X.; Cui, S.; Gu, Y.; Sun, W.; You, C.; Liu, Z.; et al. miR-19a promotes colorectal cancer proliferation and migration by targeting TIA. Mol. Cancer 2017, 16, 1-17. [CrossRef]

55. Tang, W.; Zhu, Y.; Gao, J.; Fu, J.; Liu, C.; Liu, Y.; Song, C.; Zhu, S.; Leng, Y.; Wang, G.; et al. MicroRNA-29a promotes colorectal cancer metastasis by regulating matrix metalloproteinase 2 and E-cadherin via KLF. Br. J. Cancer 2014, 110, 450-458. [CrossRef]

56. Deng, Y.H.; Deng, Z.H.; Hao, H.; Wu, X.L.; Gao, H.; Tang, S.H.; Tang, H. MicroRNA-23a promotes colorectal cancer cell survival by targeting PDK. Exp. Cell Res. 2018, 373, 171-179. [CrossRef]

57. Zhu, M.; Huang, Z.; Zhu, D.; Zhou, X.; Shan, X.; Qi, L.-W.; Wu, L.; Cheng, W.; Zhu, J.; Zhang, L.; et al. A panel of microRNA signature in serum for colorectal cancer diagnosis. Oncotarget 2017, 8, 17081-17091. [CrossRef] [PubMed] 
58. Vychytilova-Faltejskova, P.; Radova, L.; Sachlova, M.; Kosarova, Z.; Slaba, K.; Fabian, P.; Grolich, T.; Prochazka, V.; Kala, Z.; Svoboda, M.; et al. Serum-based microRNA signatures in early diagnosis and prognosis prediction of colon cancer. Carcinogenesis 2016, 37, 941-950. [CrossRef] [PubMed]

59. Matsumura, T.; Sugimachi, K.; Iinuma, H.; Takahashi, Y.; Kurashige, J.; Sawada, G.; Ueda, M.; Uchi, R.; Ueo, H.; Takano, Y.; et al. Exosomal microRNA in serum is a novel biomarker of recurrence in human colorectal cancer. Br. J. Cancer 2015, 113, 275-281. [CrossRef] [PubMed]

60. Cellura, D.; Pickard, K.; Quaratino, S.; Parker, H.; Strefford, J.; Thomas, G.; Mitter, R.; Mirnezami, A.; Peake, N. miR-19-Mediated Inhibition of Transglutaminase-2 Leads to Enhanced Invasion and Metastasis in Colorectal Cancer. Mol. Cancer Res. 2015, 13, 1095-1105. [CrossRef] [PubMed]

61. Zhang, J.; Xiao, Z.; Lai, D.; Sun, J.; He, C.; Chu, Z.; Ye, H.; Chen, S.; Wang, J. miR-21, miR-17 and miR-19a induced by phosphatase of regenerating liver-3 promote the proliferation and metastasis of colon cancer. Br. J. Cancer 2012, 107, 352-359. [CrossRef] [PubMed]

62. Pizzini, S.; Bisognin, A.; Mandruzzato, S.; Biasiolo, M.; Facciolli, A.; Perilli, L.; Rossi, E.; Esposito, G.; Rugge, M.; Pilati, P.; et al. Impact of microRNAs on regulatory networks and pathways in human colorectal carcinogenesis and development of metastasis. BMC Genom. 2013, 14, 589. [CrossRef]

63. Ellermeier, C.; Vang, S.; Cleveland, K.; Durand, W.; Resnick, M.B.; Brodsky, A.S. Prognostic microRNA expression signature from examination of colorectal primary and metastatic tumors. Anticancer Res. 2014, 34, 3957-3967.

64. Ahmed, E.K.; Fahmy, S.A.; Effat, H.; Wahab, A.H.A. Circulating miR-210 and miR-1246 as potential biomarkers for differentiating hepatocellular carcinoma from metastatic tumors in the liver. J. Med. Biochem. 2019, 38, 109-117. [CrossRef]

65. Zhang, Y.; Zhou, Y.-M.; Zhang, Z.-J.; Li, X. miR-210 is a Serological Biomarker for Predicting Recurrence and Prognosis of Colon Carcinoma Patients with Liver Metastases After Radiofrequency Ablation Treatment. Cancer Manag. Res. 2020, 12, 9077-9085. [CrossRef]

66. Drusco, A.; Nuovo, G.J.; Zanesi, N.; Di Leva, G.; Pichiorri, F.; Volinia, S.; Fernandez, C.; Antenucci, A.; Costinean, S.; Bottoni, A.; et al. MicroRNA Profiles Discriminate among Colon Cancer Metastasis. PLoS ONE 2014, 9, e96670. [CrossRef]

67. Pecqueux, M.; Liebetrau, I.; Werft, W.; Dienemann, H.; Muley, T.; Pfannschmidt, J.; Müssle, B.; Rahbari, N.N.; Schölch, S.; Büchler, M.W.; et al. A Comprehensive MicroRNA Expression Profile of Liver and Lung Metastases of Colorectal Cancer with Their Corresponding Host Tissue and Its Prognostic Impact on Survival. Int. J. Mol. Sci. 2016, 17, 1755. [CrossRef]

68. Shao, Y.; Chen, T.; Zheng, X.; Yang, S.; Xu, K.; Chen, X.; Xu, F.; Wang, L.; Shen, Y.; Wang, T.; et al. Colorectal cancer-derived small extracellular vesicles establish an inflammatory premetastatic niche in liver metastasis. Carcinogenesis 2018, 39, 1368-1379. [CrossRef] [PubMed]

69. Tsukamoto, M.; Iinuma, H.; Yagi, T.; Matsuda, K.; Hashiguchi, Y. Circulating Exosomal MicroRNA-21 as a Biomarker in Each Tumor Stage of Colorectal Cancer. Oncology 2017, 92, 360-370. [CrossRef]

70. Yin, J.; Bai, Z.; Song, J.; Yang, Y.; Wang, J.; Han, W.; Zhang, J.; Meng, H.; Ma, X.; Yang, Y.; et al. Differential expression of serum miR-126, miR-141 and miR-21 as novel biomarkers for early detection of liver metastasis in colorectal cancer. Chin. J. Cancer Res. 2014, 26, 95-103. [PubMed]

71. Nassar, F.J.; El Sabban, M.; Zgheib, N.K.; Tfayli, A.; Boulos, F.; Jabbour, M.; Saghir, N.S.E.L.; Talhouk, R.; Bazarbachi, A.; Calin, G.A.; et al. miRNA as Potential Biomarkers of Breast Cancer in the Lebanese Population and in Young Women: A Pilot Study. PLoS ONE 2014, 9, e107566. [CrossRef] [PubMed] 